\title{
Does Shunt Selection Affect the Rate of Early Shunt Complications in Neonatal Myelomeningocele-Associated Hydrocephalus? A Multi-Center Study
}

\author{
Gokmen KAHILOGULLARI ${ }^{1}$, Volkan ETUS ${ }^{2}$, Tugba MORALI GULER ${ }^{3}$, Hakan KARABAGLI ${ }^{4}$, Agahan UNLU ${ }^{1}$ \\ ${ }^{1}$ Ankara University, Faculty of Medicine, Department of Neurosurgery, Ankara, Turkey \\ ${ }^{2}$ Kocaeli University, Faculty of Medicine, Department of Neurosurgery, Kocaeli, Turkey \\ ${ }^{3}$ Karabuk University, Educational and Research Hospital, Department of Neurosurgery, Karabuk, Turkey \\ ${ }^{4}$ Selcuk University, Faculty of Medicine, Department of Neurosurgery, Konya, Turkey
}

\section{ABSTRACT}

AIM: To evaluate the effect of shunt selection on the rate of shunt revision due to early shunt complications in neonatal myelomeningocele-associated hydrocephalus.

MATERIAL and METHODS: The data of 157 neonatal myelomeningocele cases in three pediatric neurosurgery centers (Ankara University, Kocaeli University, Selcuk University) who underwent shunt surgery at the time of myelomeningocele repair between 2000 and 2014 were retrospectively analyzed. Clinical features of the patients, shunt types, and early shunt complications within the first three months were recorded. The patients were classified according to several features of the shunt systems, such as the valve type, valve size/contour and catheter type.

RESULTS: Of all patients, 71 (45.2\%) underwent early shunt revision surgery due to various complications. Mechanical complications were the most frequent cause of shunt failure, followed by infection. There was no significant difference among the valve types. Also, no significant difference was observed among the catheter types. Only valve contour/size (contoured regular/ultra-small/burr-hole/ cylindrical/neonatal) seemed to significantly affect the rate of early complications. The patients with neonatal-design valves or ultrasmall valves had significantly less complications, such as poor wound-healing, wound-dehiscence, cerebrospinal fluid leak or shunt exposure. The infection rate secondary to these complications was found to be lower.

CONCLUSION: Myelomeningocele patients with prominent hydrocephalus frequently have a friable skin, due to reduced macrocrania-related subcutaneous tissues. Small-sized (neonatal-design or ultra-small) valves may significantly reduce the early shunt complication rate among this population.

KEYWORDS: Hydrocephalus, Shunt infection, Shunt malfunction, Myelomeningocele, Neonate

\section{INTRODUCTION}

$\mathrm{M}$ yelomeningocele is a complex birth defect which affects the central nervous system at different and multiple levels $(4,5)$. Although myelomeningocele is considered as a static condition, it becomes more complicated due to the presence of associated problems. Hydrocephalus,
Chiari malformation type II, syringomyelia, and cerebral midline anomalies are the common conditions which accompany the spinal cord malformations $(12,13)$. It is well-established that only one out of six infants born with myelomeningocele presents signs of increased intracranial pressure at birth, while only one out of eight of them has a head circumference above the $98^{\text {th }}$ percentile $(4,13,14)$. Following the initial closure of 
the spinal defect, approximately $65 \%$ of the affected children develop hydrocephalus at two or three weeks of age (14).

The associated hydrocephalus, either congenital or developing following myelomeningocele closure, is a common condition in which shunt surgery is almost unavoidable (10). While endoscopic third ventriculostomy has been gaining importance in the management of hydrocephalus, children with myelomeningocele and that requiring hydrocephalus management at a younger age have the lowest success rates with this technique (14). Therefore, ventriculoperitoneal shunting remains the primary modality for the treatment of hydrocephalus in children with myelomeningocele and reported rates of shunt replacement are almost 80 to $85 \%(2,6,10)$.

On the other hand, shunt-related complications increase the patient morbidity and mortality significantly. The overall risk of shunt infection and malfunction has been reported to be higher in patients with myelomeningocele $(2,6,9)$. In addition, the risk of shunt infections is higher in patients with myelomeningocele than in those requiring shunt placements for the treatment of other conditions, whereas shunt infections have been shown to complicate 3 to $25 \%$ of the ventriculoperitoneal shunts in this patient population (6). Also, the need for multiple shunt placement procedures seems to have an adverse effect on long-term outcomes $(2,3)$. Therefore, reducing the number of revisions is of paramount importance.

In this study, we aimed to evaluate the effect of shunt selection on the rate of shunt revision due to early shunt-related complications in neonatal myelomeningocele-associated hydrocephalus.

\section{- MATERIAL and METHODS}

The data of 157 neonatal myelomeningocele cases, who underwent shunt surgery at the time of myelomeningocele repair in three pediatric neurosurgery centers (Ankara University, Kocaeli University, Selcuk University) between April 2000 and February 2014, were retrospectively analyzed. Clinical features of the patients, shunt types, and early shunt complications within the first three months were recorded. The patients, who were followed for at least one year after surgery, were included in the study.

The patients were classified according to several features of the shunt systems, such as the valve type, valve size/contour and catheter type.

According to the valve types, the patients were grouped as follows: fixed-differential-pressure valves, anti-siphon or gravity activated valves, flow-control valves and adjustable valves. Regarding the size and the contour of the valves, the patients were grouped as follows: contoured regular valves, regular bur-hole valves, cylindrical valves, and ultra-small or neonatal design valves.

According to the catheter types used, the patients were grouped as follows: antimicrobial-impregnated or -coated catheters, and standard catheters.

Early shunt complications were classified in four major categories:
1. Mechanical dysfunction (shunt obstruction, peritoneal problems)

2. Wound problems (wound-dehiscence, skin irritation, pressure sores, shunt exposure)

3. Infection

4. Dynamic malfunction (overdrainage-related problems).

A written informed consent was obtained from each patient. The study protocol was approved by the local Ethics Committee. The study was conducted in accordance with the principles of the Declaration of Helsinki.

Statistical analysis was performed using SPSS v23 software (SPSS Inc., Chicago, IL, USA). The Pearson chi-square test was used to analyze statistical significance. A $p$ value of $\leq$ 0.05 was considered statistically significant.

\section{- RESULTS}

Of 157 patients, 71 (45.2\%) underwent early shunt revision surgery due to various complications. Wound problems were the most frequent cause of early shunt revision surgery, followed by infection and mechanical complications. In terms of the four major shunt complication categories; there was no significant difference among the valve types. Also, no significant difference was found among the catheter types. Only valve contour/size seemed to significantly affect the complication rate in the categories of wound problems and infection. The data are summarized in Tables I, IIA, IIB, and IIC. The patients with neonatal-design or ultra-small valves had significantly lower rates of wound problems, such as poor wound-healing, wound-dehiscence, cerebrospinal fluid leak or shunt exposure. The infection rate was found to be lower in the valve contour/size group.

\section{DISCUSSION}

Myelomeningocele is the most complex congenital anomaly compatible with the long-term survival $(4,13,15)$. These patients require a multidisciplinary approach for the treatment of myelomeningocele and hydrocephalus management constitutes a major part in their care. Hydrocephalus in myelomeningocele may be present at birth and may sometimes develop after the repair of myelomeningocele (13). Study data indicates that the incidence of hydrocephalus and the requirement of ventriculoperitoneal shunt in these patients vary from 52 to $90 \%$ (7). According to the study of Januschek et al. (4), the shunt dependence occurred in $85 \%$ of the patients. In another study, although approximately $90 \%$ patients with myelomeningocele developed hydrocephalus requiring shunt placement, only $15 \%$ demonstrated active hydrocephalus at the time of repair surgery (5).

The management of shunts remains an important problem for these children with myelomeningocele. Despite novel techniques and technological improvements in shunt systems, the rate of shunt malfunction remains high $(4,5,13)$. According to Talamonti et al. (13), the rate of multiple shunt placement procedures was $53 \%$. In the literature, the overall risk of shunt 
infection and malfunction has been reported to be higher in patients with myelomeningocele than in those requiring shunt placements for the treatment of other conditions (9). Some authors reported that shunt-related complications were more common, serious, and often life-threatening in these children $(9,12,14)$. Recent studies also suggest that the overall survival in patients with myelomeningocele without hydrocephalus is significantly longer and the patients with myelomeningocele undergoing shunt surgery have reduced life expectancy, compared to those not requiring shunt placements for cerebrospinal fluid diversion (10). On the other hand, Tulipan et al. (16) recommended prenatal surgery for myelomeningocele patients. They suggested that this technique might reduce the hydrocephalus risk and minimize the shunt-related complications.

Table I: Patients and Postoperative Shunt Complications

\begin{tabular}{|c|c|c|c|c|c|}
\hline $\begin{array}{l}\text { Total Number of } \\
\text { Patients }\end{array}$ & $\begin{array}{c}\text { Number of } \\
\text { Patients who have } \\
\text { Undergone Early } \\
\text { Shunt Revision } \\
\text { Surgery }\end{array}$ & $\begin{array}{c}\text { Number of Cases } \\
\text { with Mechanical } \\
\text { Dysfunction }\end{array}$ & $\begin{array}{c}\text { Number of Cases } \\
\text { with Wound } \\
\text { Problems }\end{array}$ & $\begin{array}{c}\text { Number of Cases } \\
\text { with Shunt } \\
\text { Infection }\end{array}$ & $\begin{array}{l}\text { Number of Cases } \\
\text { with Dynamic } \\
\text { Malfunction }\end{array}$ \\
\hline 157 & 71 & 12 & 28 & $\begin{array}{c}23 \\
(11+12)^{\star}\end{array}$ & 8 \\
\hline
\end{tabular}

* Twelve of the 23 shunt infection cases were related to wound problems such as wound dehiscence and exposed shunt.

Table IIA: Complications Related to Valve Type

\begin{tabular}{|c|c|c|c|c|}
\hline & \multicolumn{3}{|c|}{ Valve Type } & \multirow[b]{2}{*}{ Adjustable Valves } \\
\hline & $\begin{array}{l}\text { Fixed Differential- } \\
\text { Pressure Valves }\end{array}$ & $\begin{array}{c}\text { Anti-Siphon or } \\
\text { Gravity Activated } \\
\text { Valves }\end{array}$ & $\begin{array}{c}\text { Flow-Control } \\
\text { Valves }\end{array}$ & \\
\hline Mechanical Dysfunction & 4 & 2 & 3 & 3 \\
\hline Wound Problems & 8 & 5 & 7 & 8 \\
\hline Infection & 7 & 5 & 5 & 6 \\
\hline Dynamic Malfunction & 3 & 1 & 2 & 2 \\
\hline
\end{tabular}

Table IIB: Complications Related to Valve Size/Contour

\begin{tabular}{|c|c|c|c|c|}
\hline \multicolumn{5}{|c|}{ Valve Size/Contour } \\
\hline Mechanical Dysfunction & 3 & 4 & 2 & 3 \\
\hline Wound Problems & 11 & 10 & 6 & $1^{*}$ \\
\hline Dynamic Malfunction & 2 & 3 & 1 & 2 \\
\hline \multicolumn{5}{|l|}{${ }^{*} p<0.05$} \\
\hline \multicolumn{5}{|c|}{ Table IIC: Infections Related to Catheter Type } \\
\hline Infection & \multicolumn{2}{|c|}{$9(12 \%)$} & \multicolumn{2}{|c|}{$14(19 \%)$} \\
\hline
\end{tabular}


Furthermore, infection, the major cause of morbidity and mortality, is a shunt placement-associated complication $(1,3,9)$. The poorly developed immune system of newborns, poorer skin conditions, high-skin bacterial density, reduced subcutaneous tissue due to macrocrania and multiple shunt revisions can be implicated as some of the underlying causes $(1,9,11,17)$.

Some authors have reported that ventriculosubgaleal shunting may reduce the incidence of shunt revision for infants with myelomeningocele (8). However, the aforementioned study was carried out in a very small series with only nine patients and without comparing with shunt procedures and shunt types.

Moreover, the ideal timing of shunt surgery is still controversial with recommendations of concurrent shunt placement with myelomeningocele repair and sequential treatment as myelomeningocele repair, followed by shunt insertion. Epstein was one of the first proponents of simultaneous shunt placement and myelomeningocele repair (14). Some authors provided support for simultaneous versus sequential myelomeningocele repair in 69 patients with the latter noted to have a higher rate of cerebrospinal fluid leaks (16.7 vs. $0 \%$ ) and prolonged hospital stay $(6,12,16)$. However, the overall complication rates and infection rates were similar between the study groups. According to Yilmaz et al. (17), no statistically significant difference was reported between concurrent surgery and sequential surgery by means of infection rates. Some authors described a higher infection rates in newborns with late ventriculoperitoneal shunt placement, compared to early shunt surgery (3); however, some authors reported that there were no statistically difference of shunt infection in patients with shunted early or late after myelomeningocele repair operations (9). In larger series including 170 and 69 patients, respectively, no difference in the outcome of shunt functions based on the order of the myelomeningocele repair was observed (15).

\section{- CONCLUSION}

Neonatal myelomeningocele patients with prominent hydrocephalus frequently have a friable skin, due to reduced macrocrania-related subcutaneous tissues. Small-sized (neonatal-design or ultra-small) valves may significantly reduce the early shunt complication rate in this patient population.

\section{- REFERENCES}

1. Braga MHV, de Carvalho GTC, Brandao RACS, de Lima FBF, Costa BS: Early shunt complications in 46 children with hydrocephalus. Arq Neuropsiquiatr 67: 273-277, 2009

2. Chakrabortty A, Crimmins D, Hayward R, Thompson D: Toward reducing shunt placement rates in patients with myelomeningocele. J Neurosurg Pediatrics 1: 361-365, 2008

3. Clemmensen D, Rasmussen MM, Mosdal C: A retrospective study of infections after primary VP shunt placement in the newborn with myelomeningocele without prophylactic antibiotics. Childs Nerv Syst 26: 1517-1521, 2010
4. Januschek E, Röhrig A, Kunze S, Fremerey C, Wiebe B, Messing-Jünger M: Myelomeningocele- a single institute analysis of the years 2007 to 2015. Childs Nerv Syst 16: 2016

5. Kaufman BA: Neural tube defects. Pediatr Clin N Am 51: 389419, 2004

6. Margaron FC, Poenaru D, Bransford R, Albright AL: Timing of ventriculoperitoneal shunt insertion following spina bifida closure in Kenya. Childs Nerv Syst 26: 1523-1528, 2010

7. Melo JRT, Pacheco P, Melo EN, Vasconcellos A, Passos RK: Clinical and ultrasonographic criteria for using ventriculoperitoneal shunts in newborns with myelomeningocele. Arq Neuropsiquiatr 73:759-763, 2015

8. Petraglia AL, Moravan MJ, Dimopoulos VG, Silberstein $\mathrm{HJ}$ : Ventriculosubgaleal shunting- a strategy to reduce the incidence of shunt revisions and slit ventricles: An institutional experience and review of the literature. Pediatr Neurosurg 47: 99-107, 2011

9. Radmanesh F, Nejat F, Khashab M, Ghodsi SM, Ardebili HE: Shunt complications in children with myelomeningocele: Effect of timing of shunt placement. J Neurosurg Pediatrics 3:516-520, 2009

10. Sankhla S, Khan GM: Reducing CSF shunt placement in patients with spinal myelomeningocele. J Pediatr Neurosci 4: 2-9, 2009

11. Simon TD, Whitlock KB, Cambrin JR, Kestle JR, Rosenfeld M, Dean JM, Holubkov R, Langley M, Hamblett NM: Revision surgeries are associated with significant increased risk of subsequent cerebrospinal fluid shunt infection. Pediatr Infect Dis J 31: 551-556, 2012

12. Sinha SK, Dhua A, Mathur MK, Singh S, Modi M, Ratan SK: Neural tube defect repair and ventriculoperitoneal shunting: Indications and outcome. J Neonatal Surg 1: 21, 2012

13. Talamonti G, D’Aliberti G, Collice M: Myelomeningocele: Longterm neurosurgical treatment and follow up in 202 patients. $J$ Neurosurg 107(5 Suppl): 368-386, 2007

14. Tamburrini C, Frassanito P, Lakovaki K, Pignotti F, Rendeli C, Murolo D, Di Rocco C: Myelomeningocele: The management of the associated hydrocephalus. Childs Nerv Syst 29: 15691579, 2013

15. Tuli S, Drake J, Lamberti-Pasculli M: Long term outcome of hydrocephalus management in myelomeningoceles. Childs Nerv Syst 19: 286-291, 2003

16. Tulipan N, Wellons JC, Thom EA, Gupta N, Sutton LN, Burrows PK, Farmer D, Walsh W, Johnson MP, Rand L, Tolivaisa S, D'Alton ME, Adzick NS: Prenatal surgery for myelomeningocele and the need for cerebrospinal fluid shunt placement. J Neurosurg Pediatr 16: 613-620, 2015

17. Yilmaz A, Musluman AM, Dalgic N, Cavusoglu $H$, Kanat A, Colak I, Aydın Y: Shunt insertion in newborns with myeloschisis/myelomeningocele and hydrocephalus. J Clin Neurosci 17: 1493-1496, 2010 